Yongguang Luo, Tianqi Liao, Xia Yu, Jing Li ${ }^{\star, \S}$, Libo Zhang ${ }^{\star, \S}$ and Yunhao Xi

\title{
Dielectric properties and microwave heating behavior of neutral leaching residues from zinc metallurgy in the microwave field
}

https://doi.org/10.1515/gps-2020-0011

Received August 13, 2019; accepted October 22, 2019.

Abstract: The method of microwave strengthens roasting neutral leaching slag contained germanium is put forward. The dielectric properties and temperature rising behavior of neutral leaching slag in the microwave field are analyzed via experimental and theoretical analysis. The experiment used the dielectric constant test device, the microwave roasting device and the temperature measuring device. The neutral leaching slag can absorb microwave energy and transform into heat energy. The specific surface area of the calcined slag containing the neutral leaching slag is increased by microwave roasting, and the microwave energy can reduce the particle size of the mineral particles to some extent. At the same time, cracks can be seen on the surface of the calcined sand after microwave roasting. The surface of neutral leaching slag roasted by microwave reformed cracks which help to

\footnotetext{
* Corresponding authors: Jing Li and Libo Zhang, Faculty of Metallurgical and Energy Engineering, Kunming University of Science and Technology, Kunming 650093, China; Kunming Key Laboratory of Special Metallurgy, Kunming University of Science and Technology, Kunming 650093, China; State Key Laboratory of Complex Nonferrous Metal Resources Clean Utilization, Kunming University of Science and Technology, Kunming, Yunnan 650093, China; National Local Joint Laboratory of Engineering Application of Microwave Energy and Equipment Technology, Kunming, Yunnan 650093, China; Key Laboratory of Unconventional Metallurgy, Ministry of Education, Kunming 650093, China; email: lijingkind@163.com (Jing Li), zlbpaper@163.com (Libo Zhang).

Yongguang Luo, Faculty of Metallurgical and Energy Engineering, Kunming University of Science and Technology, Kunming 650093 China; Yunnan Chihong Zn \& Ge Co., LTD, Qujing 655011, China. Tianqi Liao, Xia Yu and Yunhao Xi, Faculty of Metallurgical and Energy Engineering, Kunming University of Science and Technology, Kunming 650093, China; Kunming Key Laboratory of Special Metallurgy, Kunming University of Science and Technology, Kunming 650093, China; State Key Laboratory of Complex Nonferrous Metal Resources Clean Utilization, Kunming University of Science and Technology, Kunming, Yunnan 650093, China; National Local Joint Laboratory of Engineering Application of Microwave Energy and Equipment Technology, Kunming, Yunnan 650093, China; Key Laboratory of Unconventional Metallurgy, Ministry of Education, Kunming 650093, China.

${ }^{\S}$ These authors contributed equally to the paper.
}

open reaction channels making the oxygen to inside takes part in oxidizing reaction significantly improving germanium oxide reaction conditions, besides increasing the leaching process of the reaction area and increasing the leaching rate. The research on the dielectric constants and temperature characteristics of neutral leaching residue can provide the theoretical and experimental basis for microwave strengthen roasting.

Keywords: dielectric constants; microwave heating behavior curves; microwave roasting; germanium

\section{Introduction}

Germanium is a kind of crucial rare metal which content in the earth's crust is more than 1.5 million [1]. Germanium is a valuable strategic metal [2], widely used in defense and modern industry. Germanium is mainly used in optical fibers, infrared devices, and polymerization catalysts. Because the application of germanium is extended to new and highly valued fields, the germanium recycles from residual products become a new issue [3]. For development in the area of germanium application, the demanding of germanium is bright [4,5]. Typically, germanium is dispersed in non-ferrous metal, coal, and other minerals [6]. The neutral leaching slag is one of the leading resources of germanium metallurgy, which obtained from neutral leaching hard zinc slag of zinc smelting by pyrometallurgy [7]. The neutral leaching slag is a by-product of the zinc smelting process. The current process of germanium metallurgy is leaching by $\mathrm{HCl}$ after oxide roasting the neutral leaching residues [8]. The oxidation process needs a long time and high temperature roasted to oxide the low price elements, usually in $24 \mathrm{~h}$ and $700^{\circ} \mathrm{C}$ roasting conditions. Oxidizing roasting directly affected the leaching rate of Ge and the pressure of leaching equipment. This long term and high energy consumption roasting process seriously caused enormous energy and resource pressure.

Microwave heating as a kind of clean heating technology to start the application in the metallurgical field in recent years. Compared with conventional heating 
methods, microwave heat minerals selectively, efficiently, and automated [9-13]. Considering the advantages of microwave heating and the pressure of the environment, neutral leaching slag oxide roasting process plans to adopt microwaves.

Microwave dielectric properties play an essential role in the application of microwave heating, which expresses the capacity of the minerals of absorbing the energy from microwave [14]. When the material is in the microwave field, material produced electric dipole torque in the rapid change of the microwave field. The dipole turningdirection polarization couldn't keep up with changing in the alternating electric field to form the dielectric loss. Energy transmission of the electromagnetic field in the dielectric materials is closely related to the electromagnetic parameters. To study the feasibility of microwave roasting neutral leaching residue, the dielectric properties, and the temperature rising behavior of the neutral leaching slag are measured in this paper. Besides that, the transformation of dull leaching residue after microwave roasting is analyzed. The heat generated by the material in the microwave field is closely related to its relative dielectric constant and dielectric loss. The complex dielectric constants of metallurgical dielectric material accurate measurement are an essential significance and value of energy conservation and environmental protection. Through the analysis of dielectric constant and research of temperature rising behavioral, the basic theory of oxide roasting by microwaves can be provided. In the recovery of germanium from neutral leaching slag, the oxidizing roasting process is the primary energy consumption and directly determined the recycling efficiency of germanium. Conventional oxidation roasting usually accompanies with high energy consumption, pollution, and operating environment. Through this research, the theoretical and experimental support for microwave heating the material and microwave strengthen roasting neutral leaching residue can be provided. Besides, it very means to roast by microwave optimized the metallurgical process and conformed to the energy-saving and consumption reduction. The most important point is that microwave roasting can have a good effect on subsequent leaching.

\section{Experimental}

\subsection{Materials}

The neutral leaching slag materials used in this study are obtained from germanium smelting enterprises and acquired from the germanium production process of neutral leaching hard zinc after vacuum distillationneutral leaching residue, from Yunnan, China. 2.2. There are several measure dielectric properties of robust samples methods, including cavity perturbation, openended coaxial probes, wave-guide transmission lines, and free-space. The open coaxial probe method is most widely and accurately the method of measuring complex dielectric permittivity of materials, which is easy to use and no requirement for the sample shape.

Dielectric constants of the neutral leaching residue are measured in a high-temperature dielectric constant analyzer, which is an open-ended coaxial probe method. Taking a small amount of leaching slag into the sample tube, the sample tube is placed in a cylindrical resonant cavity with the inner dimensions are $190 \mathrm{~mm}$ height and $200 \mathrm{~mm}$ diameter, each sample is employed and compacted uniformly in a quartz tube (internal dimensions $4.1 \mathrm{~mm}$, height $52 \mathrm{~mm}$ ), which was placed inside the holder cavity, and heating by eddy current heating system. The permittivity measurement experiments are carried out from room temperature to $1200^{\circ} \mathrm{C}$ temperature at an interval of $100^{\circ} \mathrm{C}$ with a microwave frequency $2450 \mathrm{MHz}$ under air atmosphere. The Dielectric constant measurement system is shown in Figure 1.

\subsection{The equipment of testing temperature rising characteristic curve}

The heat rising characteristic curve in a microwave field is testing in a special microwave equipment made by the Key Laboratory of Unconventional Metallurgy in Yunnan, China. The sample placed in the microwave oven. This microwave equipment $(2.45 \mathrm{GHz})$ realizes the continuously adjustable power $0-3000 \mathrm{~W}$ and online real-time temperature measuring system. The structural

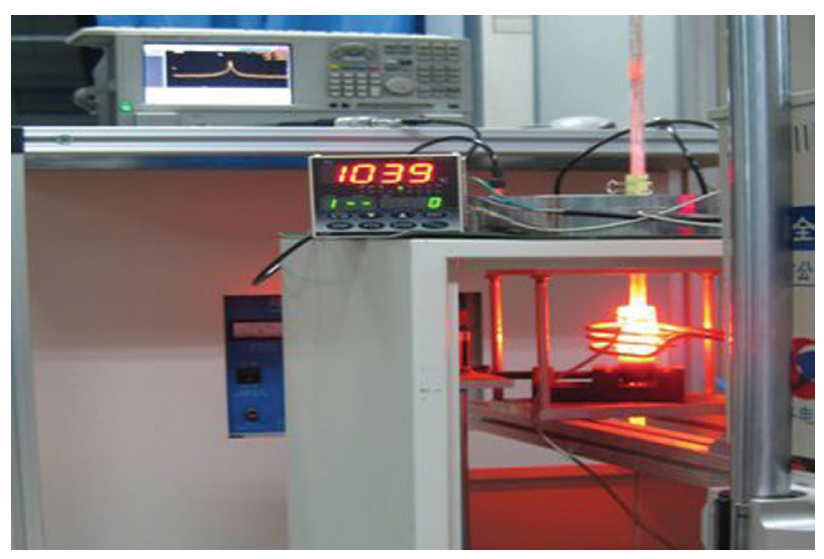

Figure 1: Dielectric constant measurement system. 
representation of this microwave device is shown in Figure 2. The temperature measuring device is shown in Figure 3.

Microwave heating depends on material internal microwave dielectric loss, which directly transfers to molecules or atoms. In the condition of enough microwave energy density, the microwave could achieve rapid heating by making material micro areas get fast energy accumulation. Microwave heating is internal heating, different from the conventional heating mode. To get the real temperature material in the microwave field, the internal temperature of the sample must be measured. This device adopts belt shielding set of thermocouple for the accurate measurement of temperature. Janney et al. [24] measured the temperature in the microwave with belt shielding set of thermocouple, and the results show the thermocouple accurately reflects the temperature of raw with the error of $2^{\circ} \mathrm{C}$. The microwave field does not affect the regular belt shielding set of thermocouple measurements. Therefore, thermocouple with belt shielding set is adopted to measure the temperature in a microwave accurately in this paper, the thermocouple (connected to the computer system) with a thin layer of aluminum shielding is employed to measure temperature, and placed at the closest proximity to the material, where the materials placed in the center of oven. The microwaves transfer from the waveguide into the microwave oven, and with input power $(1000 \mathrm{~W})$ at $2.45 \mathrm{GHz}$ frequency [21-24].

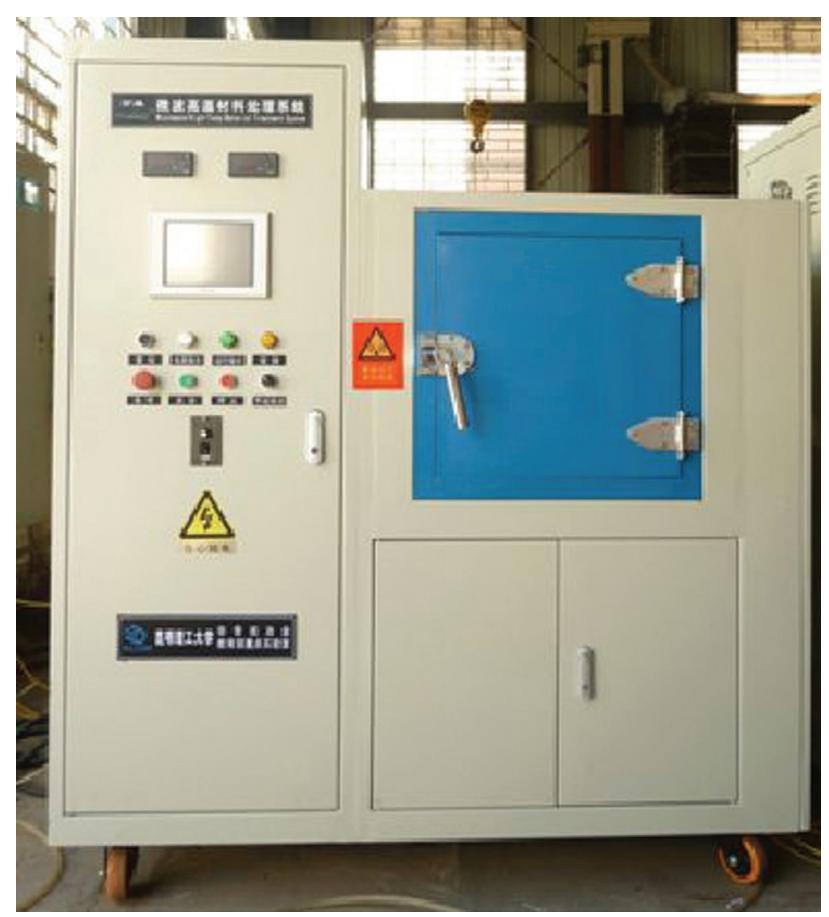

Figure 2: The apparatus of microwave roasting.

\section{Results and discussion}

\subsection{XRD and TG-DSC analysis of neutral leaching slag}

The complex nature of the dull residue mainly includes $\mathrm{Pb}, \mathrm{Fe}, \mathrm{Zn}, \mathrm{Cu}$, etc. by mineralogical analysis. Specific compositions, contents and surface morphology are detected by X-ray fluorescence spectrometry (XRF), X-Ray Diffraction (XRD) and Scanning Electron Microscope (SEM) (see Table 1 and Figures 4 and 5).

As shown in Table 1 and Figures 4 and 5, the neutral leaching slag of the raw material has a granular morphology and the monomer particles are less than $50 \mu \mathrm{m}$. Obviously, the monomer particles are very dense and free of cracks, which was not conducive to germanium leaching. The neutral leaching slag contains oxides and complex salt which composed of several oxides mainly. There is some elemental lead that existed in the leaching residue, which would volatilize in oxide process. In the leaching residue, there are zinc, $\mathrm{Fe}, \mathrm{Pb}$ mainly, which constituted the skeleton of the neutral leaching residue. Combined the treatment process of hard zinc [15-18], the primary existence forms are $\mathrm{Ge}^{2+}$ and few $\mathrm{Ge}^{4+}$ after neutral leaching. While the content of Ge is only $0.26 \%$, it could be

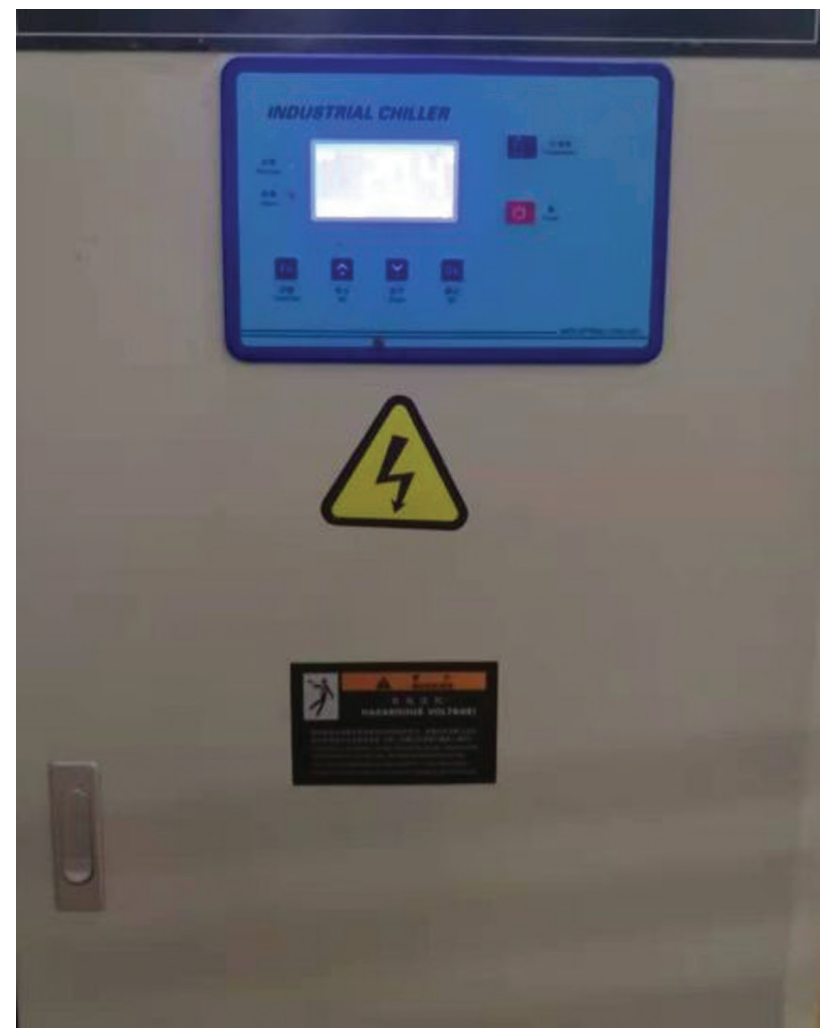

Figure 3: The temperature measuring device. 
Table 1: The main element contents of raw material.

\begin{tabular}{lccccccc}
\hline Element & Zn & Pb & Fe & S & Si & Sn & Cu \\
Content (\%) & 32.07 & 17.76 & 8.29 & 1.08 & 0.81 & 0.78 & 0.69 \\
\hline Element & Al & As & Ag & In & Ge & Ca & Bi \\
Content (\%) & 0.57 & 0.54 & 0.36 & 0.29 & 0.27 & 0.20 & 0.07 \\
\hline
\end{tabular}

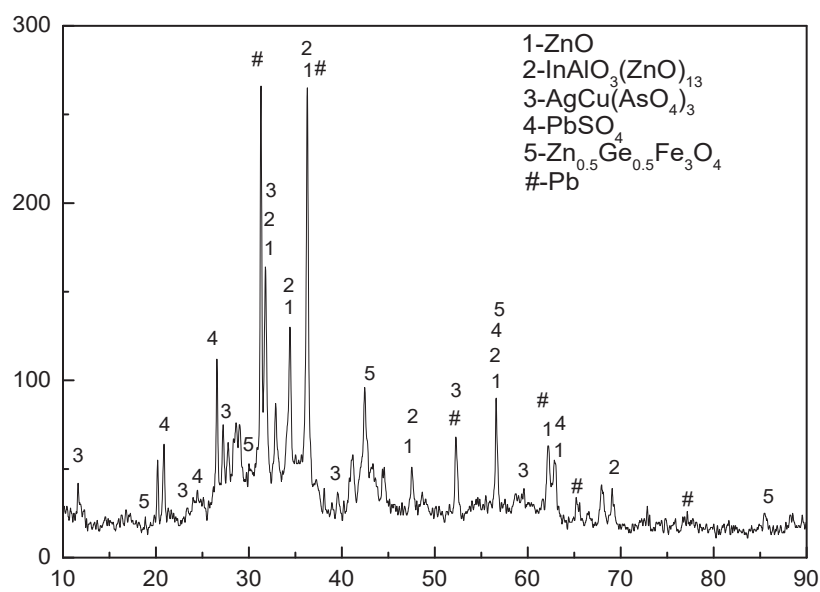

Figure 4: The XRD spectrum of raw materials.

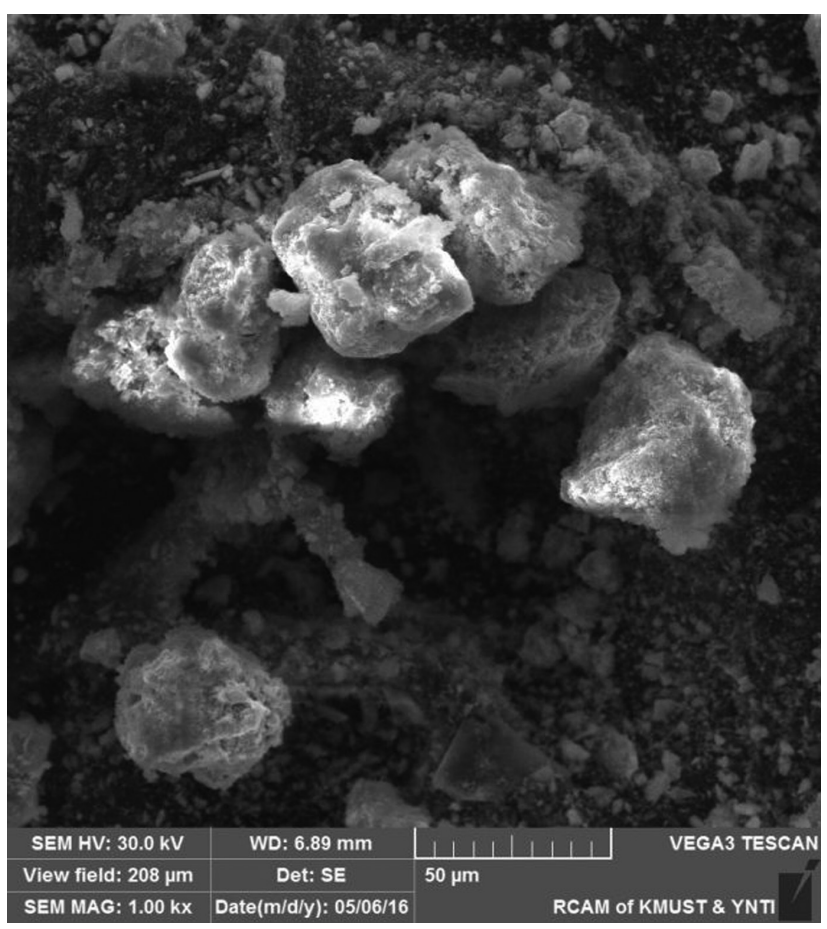

Figure 5: The SEM image of raw materials.

speculated that Ge is encapsulated and embedded in the skeleton. The primary purpose of conventional oxidation roasting is to oxidation $\mathrm{Ge}^{2+}$ and $\mathrm{As}^{3+}$, which will seriously affect the recycling of germanium and distillation equipment safety at low prices [19]. Besides that, roasting time prolonged and increasing roasting temperature, $\mathrm{GeO}_{2}$ acquired from roasting could be transformed into the insoluble form [20], which led to the low recovery rate of $\mathrm{Ge}$.

The thermogravimetric analysis of raw materials is shown in Figure 6. The result of TG analysis indicates that the leaching residue is mainly divided into three stages under air atmosphere heating process. The first stage is the drying stage from room temperature at $135^{\circ} \mathrm{C}$. Because the raw material obtained after neutral leaching, the leaching slag contained a certain amount of water. With the temperature rising, leaching slag loses weight in the drying stage. The second stage is the oxidation stage from $135^{\circ} \mathrm{C}$ to $635^{\circ} \mathrm{C}$. This stage is mainly oxidizing reaction happened. From $150^{\circ} \mathrm{C}$ to $400^{\circ} \mathrm{C}$, natural oxidation reaction took place and weight gain, such as oxidation reaction of $\mathrm{Pb}, \mathrm{As}^{3+}$. From $400^{\circ} \mathrm{C}$ to $635^{\circ} \mathrm{C}$, because of the low price of Ge start to oxide, and fewer low valence of $\mathrm{Ge}$, the weight of slag rises slowly. After $635^{\circ} \mathrm{C}$, the slag starts to lose weight again. The slag stops to put on weight with ending of the oxidation reaction. Besides, in the condition of flowing air atmosphere part of the slag is taken away by the air lead to subsequent weightlessness. The main reactions of its oxidative roasting are:

$$
\begin{aligned}
& 2 \mathrm{Zn}+\mathrm{O}_{2}=2 \mathrm{ZnO} \\
& 4 \mathrm{As}+3 \mathrm{O}_{2}=2 \mathrm{As}_{2} \mathrm{O}_{3} \\
& \mathrm{As}_{2} \mathrm{O}_{3}+\mathrm{O}_{2}=\mathrm{As}_{2} \mathrm{O}_{5} \\
& 2 \mathrm{Ge}+\mathrm{O}_{2}=2 \mathrm{GeO} \\
& 2 \mathrm{GeO}+\mathrm{O}_{2}=2 \mathrm{GeO}_{2} \\
& 4 \mathrm{In}+3 \mathrm{O}_{2}=2 \mathrm{In}_{2} \mathrm{O}_{3}
\end{aligned}
$$

The oxidation order of each substance of neutral leach residue is: $\mathrm{In}>\mathrm{As}^{3+}>\mathrm{Ge}^{2+}>\mathrm{Pb}>\mathrm{Ge}^{4+}$. In the oxidative roasting process, the reaction mainly occurs (3.4), and $\mathrm{GeO}$ is preferentially formed. The purpose of oxidizing roasting is to use the cerium in the neutral leaching slag to burn $\mathrm{GeO}_{2}$ in the oxidative roasting process to facilitate subsequent chlorination leaching, and to prevent the formation of $\mathrm{GeO}_{2}$ at high temperatures. Conversion to insoluble tetrahedron under long-term heating conditions above $550^{\circ} \mathrm{C}$, affecting the recovery of subsequent helium.

\subsection{Microwave dielectric constants}

The dielectric properties are essential to characterize the interaction between the materials and the electromagnetic 


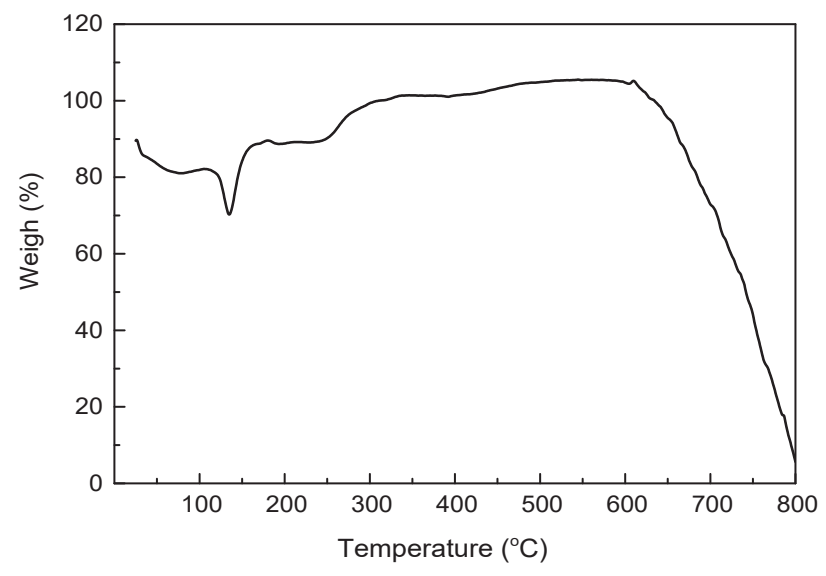

Figure 6: The TG analysis of raw material.

field. The dielectric loss is used to heat elements in the microwave field. The heating effect is determined by the dielectric constant- $\varepsilon$ of the material.

$$
\begin{aligned}
& \varepsilon=\varepsilon^{\prime}-j \varepsilon^{\prime \prime} \\
& \tan \delta=\frac{\varepsilon^{\prime \prime}}{\varepsilon^{\prime}}
\end{aligned}
$$

$\varepsilon:$ the complex dielectric constant

$\varepsilon^{\prime}$ : the real part, dielectric constant, material's capacity to absorb microwave

$\varepsilon^{\prime \prime}$ : dielectric loss factor, materials' ability of microwave energy into heat energy

$\tan \delta$ : the loss tangent value, the ratio of heat energy produced by element and the storage of the rate of microwave energy

The dielectric constant is the foundation of microwave heating. The microwave dielectric constants $\left(\varepsilon^{\prime}, \varepsilon^{\prime \prime}, \tan \delta\right)$ results of neutral leaching residue under different temperature (from room temperature to $750^{\circ} \mathrm{C}$ ) are shown as Figure 7.

The complex dielectric constants $(\varepsilon)$ are a comprehensive reflection of the dielectric polarization behavior macroscopic quantity. The dielectric constant $\left(\varepsilon^{\prime}\right)$ depends on the dielectric polarization of material. The bigger the dielectric constant, the higher the ability of binding electron. Due to the complexity of neutral leaching slag, the dielectric constant of raw material is nonlinear with the temperature changing. The loss tangent for microwave transmitter is less than 0.1 , while loss tangent for microwave absorber is more than $0.1[25]$.

Figure $7 \mathrm{a}$ is the dielectric constant variation of leaching residue under different temperature, which shows the leaching residue's degree of polarization under electromagnetic waves in the microwave field.
With the temperature rising to $500^{\circ} \mathrm{C}$, the dielectric constant of leaching slag keeps stable and stay in 3.769-4.49, which indicates that the frequency of the electromagnetic field changes and material internal polarization molecular motion frequency remains relatively stable in this condition. Combined with Figure 6, oxidation reactions happened, and new oxide formed in the temperature rising from room temperature to $500^{\circ} \mathrm{C}$. The dielectric constant is increased from 4.49 to 7.405 , with the temperature rising from $500^{\circ} \mathrm{C}$ to $700^{\circ} \mathrm{C}$, which are mainly due to the oxidation reaction is over, and the material in the slag is stable. Roasting slag components have little effect on the polarization degree, which mainly embodied in the influence of temperature on the dielectric relaxation process. Dielectric relaxation time deduct according to the temperature goes up, and then the dielectric constant goes up in this temperature ranges.

Figure $7 \mathrm{~b}$ is the dielectric loss variation of leaching residue under different temperature, which shows the leaching residue's ability to convert microwave energy to heat in the microwave field. With the temperature rising to $300^{\circ} \mathrm{C}$, the dielectric loss of leaching slag is increased from 0.0993 to 0.177 when the temperature is $150^{\circ} \mathrm{C}$, and then dielectric loss decreased to 0.0543 with the temperature at $300^{\circ} \mathrm{C}$. In Figure 4, there is a water loss peak in $\mathrm{TG}$ caves at $150^{\circ} \mathrm{C}$. Subsequently, weight increased with the temperature rising from $150^{\circ} \mathrm{C}$ to $300^{\circ} \mathrm{C}$. Because of the effect of moisture content in the slag, the dielectric loss at room temperature to $150^{\circ} \mathrm{C}$ reaches a maximum and then began to decline when the temperature is over $150^{\circ} \mathrm{C}$. The increase of dielectric loss is mainly due to the keen ability to absorb and converting microwave energy to heat energy of water. When the temperature reaches $150^{\circ} \mathrm{C}$ to $300^{\circ} \mathrm{C}$, with the leaching residue dehydration, the dielectric loss reduced. The dielectric loss increased from 0.0543 in $300^{\circ} \mathrm{C}$ to 0.26 at $450^{\circ} \mathrm{C}$, then fell to 0.103 at $500^{\circ} \mathrm{C}$. The leading cause of appearing this kind of change is that the oxidation reaction is beginning and new oxidation product formed in $300-450^{\circ} \mathrm{C}$, for example, $\mathrm{Fe}^{2+}$ oxide to $\mathrm{Fe}^{3+}$, $\mathrm{As}^{3+}$ oxide to $\mathrm{As}^{5+}$. Fresh material for this stage is the main factor influencing the dielectric loss factor. So the dielectric loss factor raised in the temperature scope. Its rising size is determined by the oxidation products of the dielectric loss factor. From $500-650^{\circ} \mathrm{C}$, dielectric loss keeps stable and maintains between 0.0994 to 0.103 . At $700^{\circ} \mathrm{C}$, the dielectric loss factor reduces to 0.0148 . The main reasons for this situation are that leaching slag oxidation reaction is fundamentally complete, germanium oxide ignored by germanium content too little, materials in the slag are 


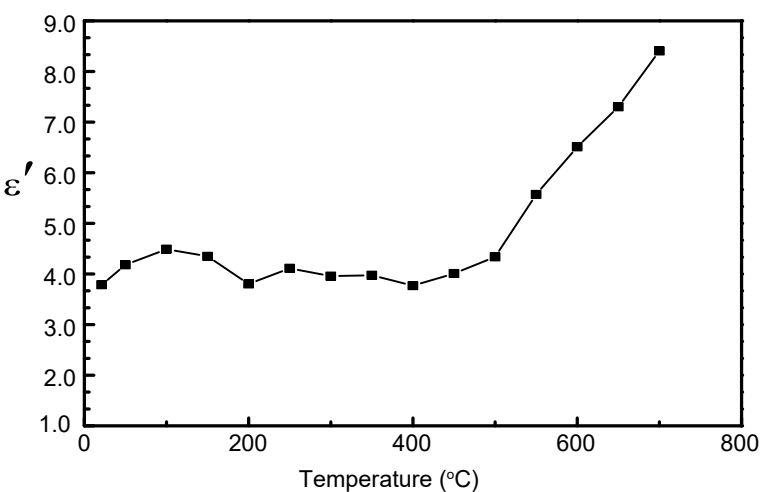

(a) the real part of complex dielectric constants

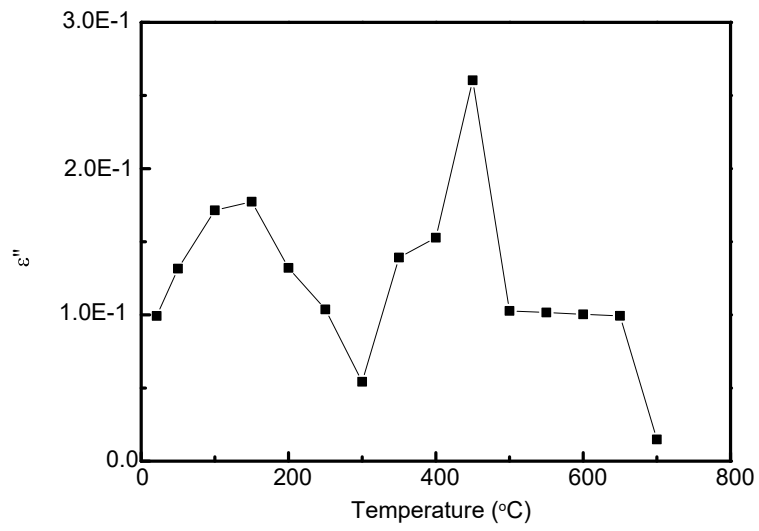

(b) the imaginary part of complex dielectric constants

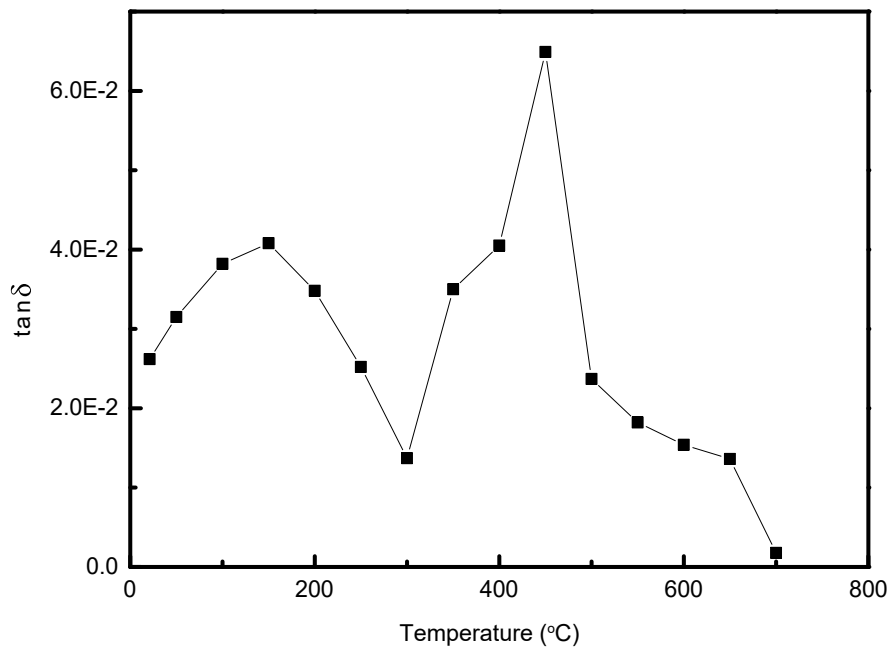

(c) the loss tangent of complex dielectric constants

Figure 7: The relationship between dielectric constants and temperature.

staying stability at this time. The dielectric loss factor is mainly affected by electric field changes in frequency and polar molecule movement lag decision. Combined with Figure $7 \mathrm{a}$, in this temperature range, polarization between molecular motion frequency and electric field changes in frequency lag is reduced, the roasting slag in molecular polarization degree increasing, the friction resistance is reduced, the degree of polarization tends to be stable, so the dielectric loss factor tends to be permanent. At $700^{\circ} \mathrm{C}$, due to further reduce the lag between the polarization of molecular motion frequency and electric field changes in frequency, both synchronized, also reduce the dielectric loss factor.

Figure $7 \mathrm{c}$ is the loss angle tangent value variation of leaching residue under different temperature, which shows the ratio between heat energy produced by material and storage of microwave energy in a cycle under electromagnetic waves in the microwave field. Figure $7 \mathrm{c}$ is similar to Figure $7 b$.

\subsection{Temperature characteristic curves}

Microwave heating, different from conventional heating, is internal heating, which is no heat to the environment. Microwave penetration depth plays a vital role in evaluating heating efficiency. Temperature rising behavior experiments adopt $30 \mathrm{~mL}$ wave-transparent crucible to reduce heat preservation difficult. The effects of different microwave power on temperature increasing behavior are exhibited in Figures 7 and 8. The outcomes reveal the same amount of materials, under the fixed contact area, different the effect of microwave power on the leaching residue heat behavior. As Figure 8 shown, with the rising microwave power, the heating rate becomes faster. The temperature is stability in the whole heating up process after $35 \mathrm{~min}$ in the microwave field.

With the microwave output power increased, the microwave radiation energy on the material per unit area is higher. The materials absorb more microwave energy and 


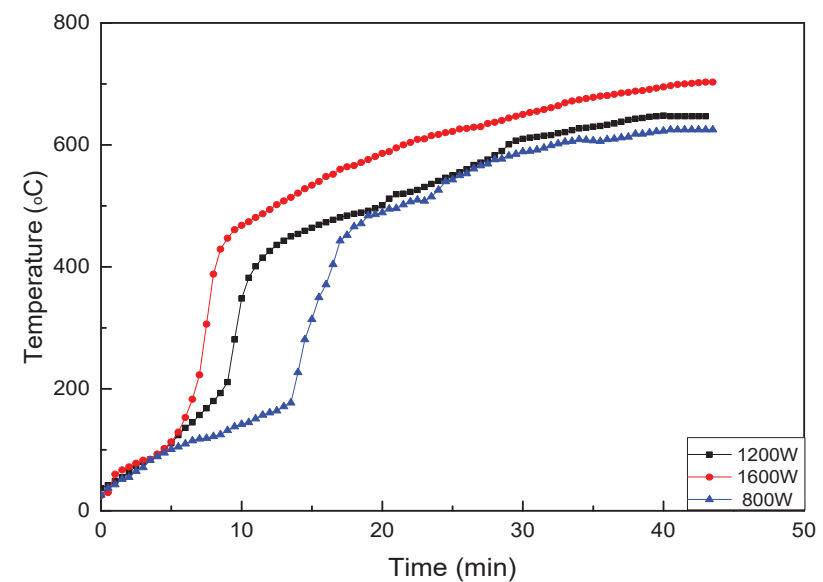

Figure 8: The temperature curve of different microwave power.

heat up more quickly. As Figure 8 shown, in microwave heating 0 to $5 \mathrm{~min}$, the heating rate of the content under different power stays the same. After heating for $5 \mathrm{~min}$, the heating rate starts to change the power of the microwave. Appearing this circumstance may be that the microwave power cannot be turned suddenly, which needs about 5 min to maintain a relatively stable control. When the temperature of the neutral leaching slag reaches $200^{\circ} \mathrm{C}$, the heating rate suddenly increased. It indicates that high dielectric constant materials may be reformed. Combined with the raw material, it is possible that oxidation reaction happened. When the temperature over $470^{\circ} \mathrm{C}$, the temperature of materials rises at a slower pace. While in Figure $7 \mathrm{~b}$, dielectric loss keeps steady, which verified the accuracy of constant dielectric measurements. According to the dielectric loss trend analysis, materials will heat slowly to $700^{\circ} \mathrm{C}$, and after $700^{\circ} \mathrm{C}$, the warming trend became further reduce the microwave field.

From Figure 8, leaching residue in the microwave field can be heated up, and temperature could be rising as high as $712^{\circ} \mathrm{C}$ under the experimental conditions. Boost microwave power in accelerating leaching slag temperature has certain advantages, but to avoid sintering, microwave power of $1200 \mathrm{~W}$ is suitable for this leaching residue. The heating curve of Figure 8 complies with the principle of Figure 7.

The temperature rising trend in Figure 9 is similar to Figure 8; no need to be repeated explanation. However, with an increase in the number of materials, the fewer materials to heat up more quickly heated in a short time with the same microwave power. As Figure 9 shown, in the same microwave power, the smaller thickness can reach a higher temperature $813^{\circ} \mathrm{C}$. Fixing the crucible surface area, the experimental process changes the amount and thickness of materials. Figure 9 explained to us the

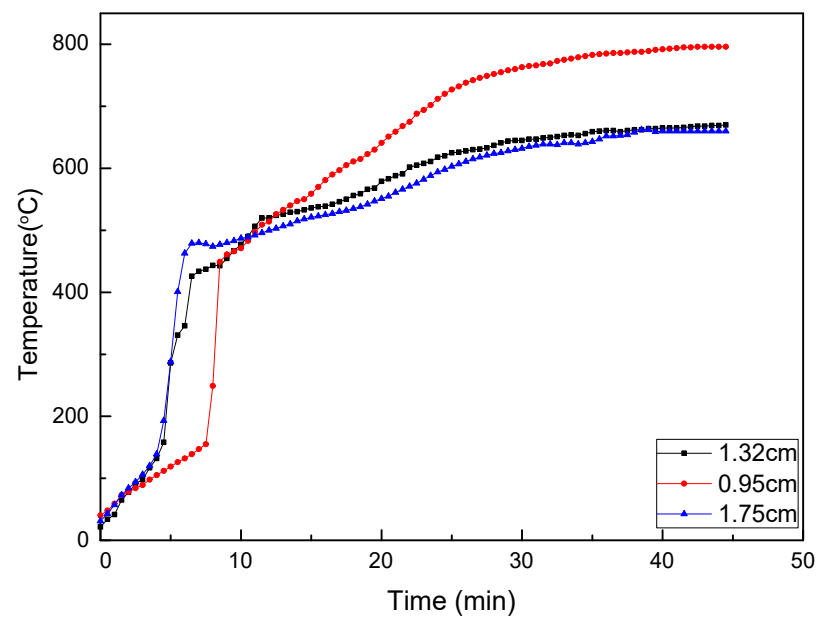

Figure 9: The temperature characteristic curve of different material layer thicknesses.

relationship between material breadth and microwave penetration depth. When the penetration depth is greater than the material thickness, the effect of penetration depth on microwave roasting of materials is small. On the other hand, the penetration depth is the main factor. When microwave energy absorbed by the leaching residue in 0-5 min, the heating rate of the material thickness of $1.32 \mathrm{~cm}$ and $1.75 \mathrm{~cm}$ stay the same. While the material's diameter of $0.95 \mathrm{~cm}$ still warms up slowly. It is mainly that the microwave can penetrate materials, and the leaching residue was not fully absorbed this part of the microwave energy. That shows microwave penetration depth is greater than the material thickness of $0.95 \mathrm{~cm}$. In the subsequent stage of warming, leaching slag heating curves of $1.32 \mathrm{~cm}$ and $1.75 \mathrm{~cm}$ thickness show that microwave is not enough to penetrate materials. And the two lines heat up almost overlapping. That shows in this stage microwave penetration depth, which is not enough to penetrate the thickness of the material layer is the primary influence factor on the microwave roasting. At this stage, the microwave penetration depth is $1.32 \mathrm{~cm}$ or less. This also provides reference data for the selection of material thickness for subsequent experiments.

\subsection{Compared to microwave and conventional roasting}

Conventional roasting adopted coke to heat up in an open environment, which leads to a large amount of loss of heat. To the oxide of $\mathrm{Ge}$ and As, conventional roasting usually roast neutral leaching hard zinc at $700^{\circ} \mathrm{C}$ for about $24 \mathrm{~h}$. This process not only seriously caused colossal energy consumption and resource pressure but 


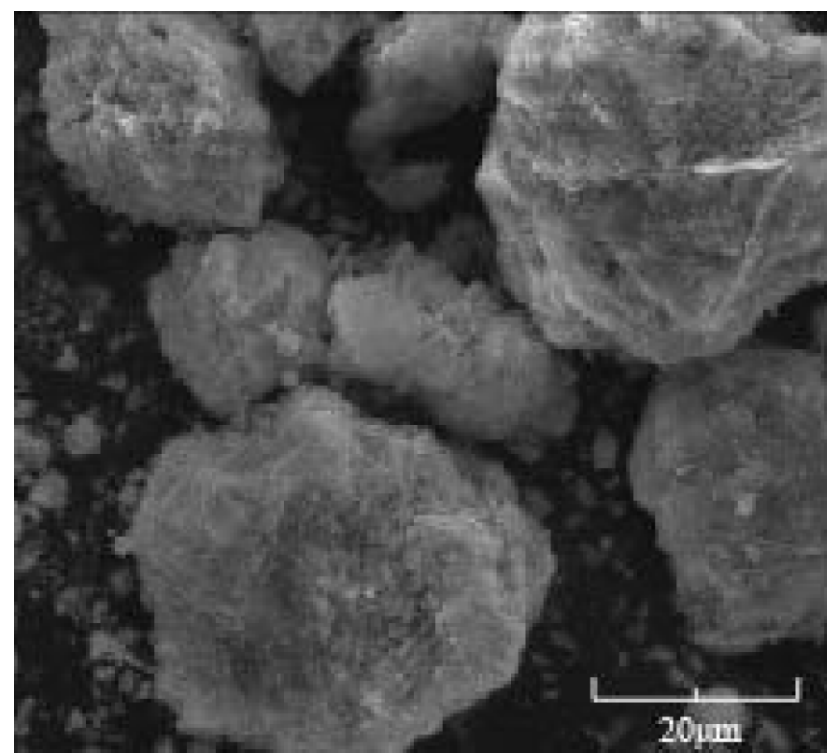

(a) conventional roasting slag 1

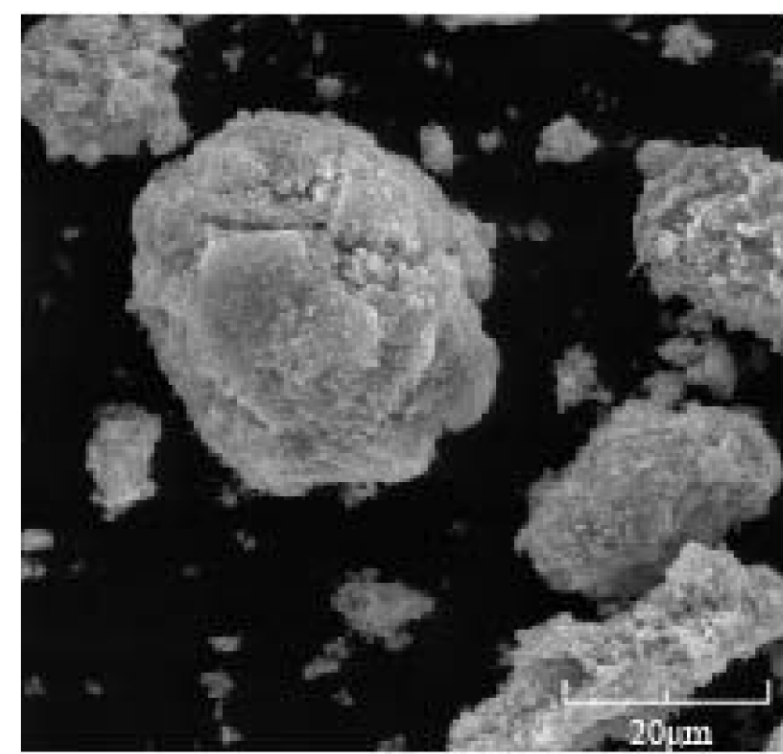

(b) microwave roasting slag 2

Figure 10: SEM images of oxidizing roast slag using conventional and microwave roasting.

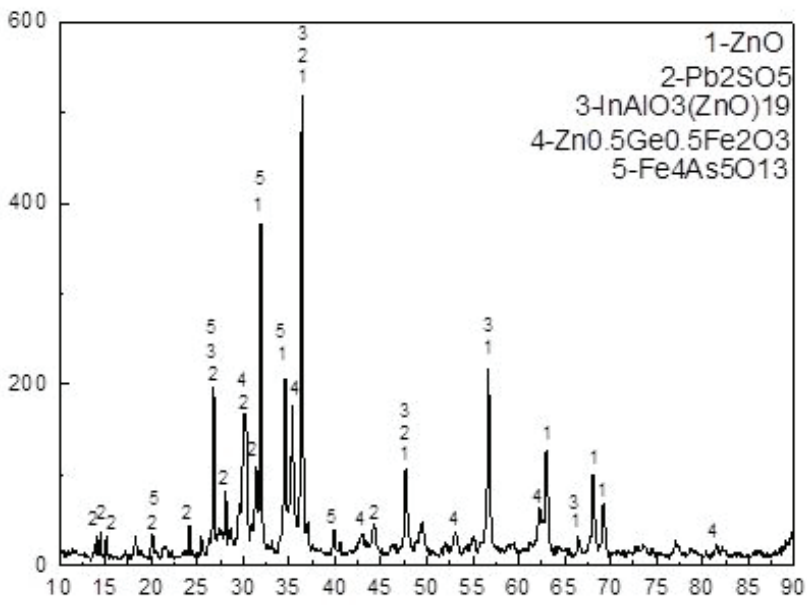

(a) conventional roasting slag 1

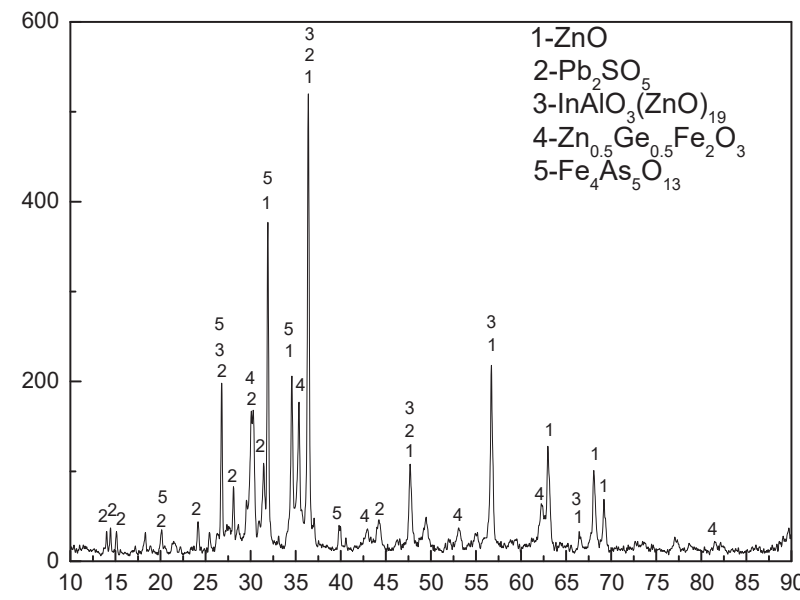

(b) Microwave roasting slag 2

Figure 11: XRD spectrums of oxidizing roast slag using conventional and microwave roasting.

also made soluble germanium to reform insoluble form. There is no advantage in dissolution germanium from the oxidizing roast slag. While roasting neutral leaching slag by microwave, cracks can be observed clearly on the surface of the raw materials. That because microwave selective heats polar molecules, which make mineral grains internal heating uneven, thermal stress crack of the mineral surface is produced. In the conventional heating mode, mineral thermal heat transfer relies on the environment, and cannot make cracks on the mineral particle surface.

Oxidizing roast slag obtained from oxidizing roasting neutral leaching slag enters to chlorination leaching process, and the leaching process has not retro the model generated by the product layer. The impact of restrictive leaching link is leaching agent in the spread of the ash diffusion layer. Strengthening the germanium recycle process commonly uses the method of increasing leaching agent concentration, leaching temperature, improving the liquid-solid ratio, and grinding to increase the contact area between mineral and leaching agents. As shown in Figures 10 and 11, the mineral particle surface generates crackle after microwave roasting, which would help to open reaction channels making the oxygen inside take part in the oxidizing reaction which significantly improved germanium oxide reaction conditions. Besides that, it 
also could increase the reaction area of the subsequent germanium leaching process to improve the leaching rate. There is no change in the mineral surface after conventional muffle furnace roasting. After microwave roasting, the composition of the phase in the calcined sand was stable, and the content of each substance in the calcined sand changed. The phases of conventional roasting slag are roughly the same as that of microwave roasting slag. In a word, the phase of the slag obtained by microwave roasting could achieve the requirements of oxidizing roasting and neutral leaching slag roasted by microwave help to improve the dynamic conditions in the subsequent germanium leaching process.

\section{Conclusions}

By experimental research, this paper has the following conclusions:

(1) Microwave roasting neutral leaching residue contained germanium is feasible. The temperature rising behavior and the electric constants show that the neutral leaching slag can absorb microwave energy and transform into heat energy.

(2) The heating rate of neutral leaching slag changes with the microwave power and the thickness of the material in the same contact area. The content can be heated up to $813^{\circ} \mathrm{C}$ at most under $0.95 \mathrm{~cm}$ thickness and $1200 \mathrm{~W}, 2.45 \mathrm{GHz}$ conditions in a microwave field.

(3) The surface of neutral leaching slag roasted by microwave reformed cracks which help to open reaction channels making the oxygen inside to take part in the oxidizing reaction, which significantly improved germanium oxide reaction conditions. Besides that, it could also increase the subsequent germanium leaching process of the reaction area and leaching rate.

(4) The dielectric property and temperature curve of leaching residue fit completely, guaranteeing the experimental accuracy. Through research on the dielectric constants and temperature characteristics of the neutral leaching slag, the results provide the theoretical and empirical basis for microwave strengthen roasting.

Acknowledgments: The authors are grateful for the financial support by the Yunnan Provincial Science and technology key project (NO. 2017FA026), National Natural Science Foundation of China (No.51404115), Yunan Ten
Thousand Talents Plan Young \& Elite Talents Project, and Kunming Academician Workstation of Advanced Preparation for Superhard Materials Field.

\section{References}

[1] Li D., Li B., Progress on the analysis of trace germanium. Metall. Anal., 2010, 30, 33-38.

[2] Song Q.M., Zhang L.G., Xu Z.M., Kinetic analysis on carbothermic reduction of $\mathrm{GeO}_{2}$ for germanium recovery from waste scraps. J. Clean Prod., 2019, 207, 522-530.

[3] Fátima A.T., Constantino F.P., Esther G.V., Yolanda L., Carlos L., Luis V., et al., Low environmental impact process for germanium recovery from an industrial residue. Miner. Eng., 2018, 128, 106-114.

[4] David E.G., Germanium statistics and information. U.S. Geological Survey, Mineral Commodity Summaries, 2012, 1-64.

[5] Wu X.L., Recovery of gallium and germanium from zinc residue. Central South University, 2013.

[6] Chen W.S., Chang B.C., Chiu K.L., Recovery of germanium from waste Optical Fibers by hydrometallurgical method. J. Chem. Eng., 2017, 5, 5215-5221.

[7] Peng J.R., Wang J.K., Yang D.J., Wang K., Enriching germanium from zinc concentrate containing rich germanium. J. Chin. Rare Earth Soc., 2008, 26, 606-608.

[8] Zhang L.B., Guo W.Q., Peng J.H., Li J., Lin G., Yu X., Comparison of ultrasonic-assisted and regular leaching of germanium from by-product of zinc metallurgy. Ultrason. Sonochem., 2016, 31, 143-149.

[9] Liu J.H., Xiao S.J., Shen Z.G., Xu L., Zhang L.B., Peng J.H., Study on the oxidative stabilization of polyacrylonitrile fibers by microwave heating. Polym. Degrad. Stabil., 2018, 150, 86-91.

[10] Reinosa J.J., García-Baños B., Catalá-Civera J.M., Fernández J.F., A step ahead on efficient microwave heating for kaolinite. Appl. Clay Sci., 2019, 168, 237-243.

[11] Forster J., Maham Y., Bobicki E.R., Microwave heating of magnesium silicate minerals. Powder Technol., 2018, 339, 1-7.

[12] Fan H., Zheng H., Li Z., Preparation of $\mathrm{Cu} / \mathrm{ZnO} / \mathrm{Al}_{2} \mathrm{O}_{3}$ catalyst under microwave irradiation for slurry methanol synthesis. Front. Chem. Sci. Eng., 2010, 4, 445-451.

[13] Pickles C.A., Microwave heating behaviour of nickeliferous limonitic laterite ores. Miner. Eng., 2004, 17, 775-784.

[14] Pickles C.A., Microwave in extractive metallurgy: Part 1 - Review of fundaments. Miner. Eng., 2009, 22, 1102-1111.

[15] Liu F., Liu Z., Li Y., Wilson B.P., Lundström M., Extraction of Ga and $\mathrm{Ge}$ from zinc refinery residues in $\mathrm{H}_{2} \mathrm{C}_{2} \mathrm{O}_{4}$ solutions containing $\mathrm{H}_{2} \mathrm{O}_{2}$. Inter. J. Miner. Process., 2017, 163, 14-23.

[16] Zhou T., Zhong X., Zheng L., Recovering In, Ge and Ga from zinc residues. JOM, 1989, 41, 36-40. 
[17] Deng M.L., Xie B., In and Ge integrate recovery during Zn metallurgy. Rare Metals and Cemented Carbides, 2007, 35, 21-24.

[18] Han L., Yang B., Dai Y., Liu D.C., Applications of vacuum metallurgical technology in recovery of secondary zinc-based resources. Vacuum, 2008, 45, 20-22.

[19] Pu S.K., Yan Y.N., Lan Y.Z., Recovery of Germanium with sodium hydroxide pretreatment-hydrochloric acid distillation method. Journal of Kunming University of Science and Technology (Natural Science Edition) (in Chinese), 2012, 37, 19-22.

[20] Mathew K.T., Raveendranath U., Cavity perturbation techniques for measuring dielectric parameters of water and other allied liquids. Sensors Update, 2000, 7, 185-210.

[21] Deshpande M.D., Reddy C.J., Tiemsin P.I., Cravey R., A new approach to estimate complex permittivity of dielectric materials at microwave frequencies using waveguide measurements. IEEE T. Microw. Theory, 1997, 45, 359-366.

[22] Seo П.S., Chin W.S., Lee D.G., Characterization of electromagnetic properties of polymeric composite materials with free space method. Compos. Struct., 2004, 66, 533-542.

[23] Nelson S.O., Bartley Jr. P.G., Measuring frequency-and temperature-dependent dielectric properties of food materials. IEEE T. Instrum. Meas., 2000, 46, 1733-1736.

[24] Janney M.A., Kimrey H.D., Schmidt M.A., Kiggans J.O., Grain growth in microwave-annealed alumina. J. Am. Ceram. Soc., 1991, 74, 1675-1681.

[25] Alias N., Zaini M.A.A., On the view of dielectric properties in microwave-assisted activated carbon preparation. Asia-Pac. J. Chem. Eng., 2016, 10, 953-960. 